\title{
Low-dose paclitaxel synergizes with oncolytic adenoviruses via mitotic slippage and apoptosis in ovarian cancer
}

\author{
CK Ingemarsdotter, SK Baird, CM Connell, D Öberg, G Halldén and IA McNeish \\ Centre for Molecular Oncology and Imaging, Institute of Cancer, Barts and the London School of Medicine, Queen Mary University \\ of London, London, UK
}

\begin{abstract}
The microtubule-stabilizing drug paclitaxel has activity in relapsed ovarian cancer. dl922-947, an oncolytic adenovirus with a 24-bp deletion in E1A CR2, replicates selectively within and lyses cells with a dysregulated $\mathbf{R b}$ pathway and has efficacy in ovarian cancer. In the aggressive A2780CP xenograft, combination treatment with weekly $d l 922-947$ and paclitaxel has significantly greater efficacy than either treatment alone and can produce complete tumor eradication in some animals. We investigated the mechanisms of paclitaxel's synergy with dl922-947 in ovarian cancer. The host-cell microtubule network is grossly rearranged and stabilized following adenovirus infection, but paclitaxel does not increase this significantly. Paclitaxel does not synergize by increasing infectivity, viral protein expression or virus release. However, destabilizing the microtubule network with nocodazole reduces viral exit, revealing a novel microtubule-dependent pathway for non-lytic adenoviral exit. di922-947 can override multiple cell cycle checkpoints but induces cell death by a non-apoptotic mechanism. In combination, $d l 922-947$ and low-dose paclitaxel induces aberrant, multipolar mitoses, mitotic slippage and multinucleation, triggering an apoptotic cell death.
\end{abstract}

Oncogene (2010) 29, 6051-6063; doi:10.1038/onc.2010.335; published online 23 August 2010

Keywords: oncolytic adenovirus; paclitaxel; mitosis; apoptosis; microtubule

\section{Introduction}

Paclitaxel is a microtubule-stabilizing drug with significant activity in ovarian cancer (McGuire et al., 1996). Regimes containing weekly low-dose paclitaxel are highly effective (Katsumata et al., 2009), even in tumors resistant to conventional three-weekly administration (Markman et al., 2002; Le et al., 2006). Although paclitaxel can stabilize microtubules at nanomolar concentrations (Jordan et al., 1993),

Correspondence: Professor IA McNeish, Centre for Molecular Oncology and Imaging, Barts and the London School of Medicine, John Vane Science Centre, Charterhouse Square, London EC1 M 6BQ, UK.

E-mail: i.a.mcneish@qmul.ac.uk

Received 24 November 2009; revised 12 May 2010; accepted 31 May 2010; published online 23 August 2010 the cell cycle effects of low-dose exposure are complex and include mitotic slippage and catastrophic mitotic exit (Paoletti et al., 1997).

Oncolytic viruses are a new class of anti-cancer treatment, based upon their ability to replicate selectively within malignant cells. The adenovirus $d / 922-947$ harbors a 24-bp deletion in E1A CR2 and induces cell death selectively in cells with a defective Rb/G1-S checkpoint pathway (Heise et al., 2000), a finding observed in over 90\% human cancers (Sherr and McCormick, 2002). Clinical trials of E1A CR2-deleted adenoviruses have commenced (http://www.clinicaltrials. gov; reference NCT00805376). E1A CR2 is important for binding to $\mathrm{pRb}$, which releases $\mathrm{E} 2 \mathrm{~F}$ with the consequent transactivation of genes driving S-phase entry and cell cycle progression (Felsani et al., 2006). We have previously shown that $d l 922-947$ has high oncolytic efficacy in ovarian cancer (Lockley et al., 2006), by a mechanism independent of classical apoptosis (Baird et al., 2008), but involving abrogation of multiple cell cycle checkpoints (Connell et al., 2008).

Clinical trials with the adenovirus $d l 1520$ (Onyx-015) suggested that combinations with chemotherapy are effective (Hecht et al., 2003). Paclitaxel can synergize with oncolytic adenoviruses in various tumor models (AbouEl Hassan et al., 2006; Cheong et al., 2008). Suggested mechanisms include increased E1A (AbouEl Hassan et al., 2006) and cell surface receptor expression (Seidman et al., 2001). However, the interactions between adenoviruses and paclitaxel remain unclear and understanding them will facilitate future trial design.

Adenoviruses induce microtubule alterations after infection (Staufenbiel et al., 1986), including early stabilization (Warren et al., 2006). The importance of the microtubule network for adenovirus entry and nuclear translocation is well-characterized. After internalization, the viral capsid interacts with the motor protein dynein and travels with net movement toward the nucleus in a microtubule-dependent manner (Leopold and Crystal, 2007). However, little is known about microtubules in adenoviral exit. Exit has been associated with the collapse and cleavage of the vimentin and cytokeratin networks (Belin and Boulanger, 1987; White and Cipriani, 1989) and E3 11.6 (Adenovirus Death Protein) may be important in very late cell lysis (Tollefson et al., 1996). However, virus can be detected in the supernatant long before cell lysis, suggesting a pathway of continuous release. 
Here, we have investigated how paclitaxel synergizes with dl922-947 in ovarian cancer and whether changes in microtubules influence this. We describe three novel findings. Firstly, dl922-947 induces an abnormal microtubule network and an increase in microtubule stability independently of paclitaxel. Secondly, we describe a role for microtubules in non-lytic virus exit. Thirdly, we demonstrate that paclitaxel synergizes with dl922-947 by deregulating the activity of mitosis-promoting factors, leading to mitotic slippage, multinucleation and apoptosis induction.

\section{Results}

The oncolytic adenovirus d1922-947 synergizes with low-dose paclitaxel in ovarian cancer dl922-947 has significant activity against IGROV1 xenografts (Lockley et al., 2006), but little against A2780CP (Flak et al., 2010). To test whether paclitaxel can augment dl922-947 activity in vivo, we used two different regimes. In the first, mice bearing intraperitoneal (i.p.) A2780CP-luciferase xenografts received three weekly doses of i.p. dl922-947 and/or $20 \mathrm{mg} / \mathrm{kg}$ paclitaxel. Combination treatments were separated by $24 \mathrm{~h}$, with virus injected first. In this highly aggressive model, mice in the vehicle group developed disseminated disease within peritoneum and pelvis by day 24 . As before, treatment with either $d l 922-947$ or paclitaxel alone was ineffective. However, when combined with paclitaxel, a significant reduction in tumor burden was seen at day 38 compared with paclitaxel alone (Figure 1a, left; $P=0.046$ ).

A second in vivo regime was tested in which paclitaxel was fractionated into four daily doses of $5 \mathrm{mg} / \mathrm{kg}$ commencing $24 \mathrm{~h}$ after $d 1922-947$. As before, tumors in mice receiving $d l 922-947$ grew exponentially (Figure 1a, right). Fractionation of the paclitaxel appeared to improve its activity compared with dl922-947 alone, although differences in radiance did not reach statistical significance $(P=0.06-0.09)$. However, a significant reduction in tumor growth was still observed in the group receiving $d l 922-947$ plus paclitaxel $(P=0.044)$. When the last mouse in the paclitaxel group was killed because of tumor burden (day 56), three mice in the combination group remained alive with no tumors detectable by bioluminescence or necropsy. Livers from experiment 1 were examined (Figure 1c). In the vehicle group, livers were healthy, whereas those from the paclitaxel group showed necrosis and hemorrhage. We observed hepatotoxicity in some dl922-947-treated mice, as previously (Lockley et al., 2006), with thickening of the capsule and inflammatory cell infiltration; this was increased in the combination group.

To model this synergy in vitro, we infected A2780CP cells and added low-dose (3nm) paclitaxel up to $72 \mathrm{~h}$ post-infection (p.i.). Paclitaxel increased the efficacy of dl922-947, with the greatest effect seen when chemotherapy was added $24 \mathrm{~h}$ p.i. (Figure 1d, left). Combination treatment also led to a marked reduction in EC50 in
IGROV1 cells, using two doses of paclitaxel (Figure 1d, right), confirming that the effect is not cell-specific. The synergy was unrelated to primary adenovirus infection as low-dose paclitaxel had no effect on cell surface CAR expression in either cell line and did not increase infectivity by Ad5 vectors, whether given before or after virus (data not shown).

\section{Use of fluorescent adenovirus to assess replication and virus exit}

We hypothesized that paclitaxel/dl922-947 synergy may result from alterations to microtubules. To visualize these, we constructed a derivative of $d l 922-947$, dlCR2pIX-dsRed, in which the minor capsid protein pIX is fused to the fluorescent protein dsRed, as others have done with green fluorescent protein (GFP) (Le et al., 2004; Meulenbroek et al., 2004). The modified viral capsid did not reduce cytotoxic efficacy (Supplementary Figure 1) and $d l C R 2-p I X-d s R e d$ could be detected in proximity to, and within, the nucleus of IGROV1 cells as early as $1 \mathrm{~h}$ post-infection (Figure 2a, left). We also detected viral particles being released from cells $48 \mathrm{~h}$ p.i., showing that $d l$ CR2-pIX-dsRed is a useful tool to study adenovirus intracellular trafficking and exit. We detected a time-dependent increase in emitted fluorescence from $d l$ CR2-pIX-dsRed-infected cells (Figure 2b), which correlated closely with intracellular virion titer (Figure 2c; $r^{2}=0.8999$ ). Thus, dlCR2-pIX-dsRed can also be used for indirect measurement of intracellular viral replication.

\section{Adenovirus induces rearrangements and stabilization of the microtubule cytoskeleton in ovarian cancer cells}

To investigate host-cell microtubules, A2780CP cells were analyzed by confocal microscopy $48 \mathrm{~h}$ after $d l$ CR2-pIX-dsRed infection (Figure 3a). Microtubules were rearranged in a circular formation compared with the radial organization in uninfected cells. Strikingly, abnormal microtubule organization was also seen in IGROV1 cells, with clustered or aggregated structures (Figure 3b). We used three methods to investigate the effects of combined virus and paclitaxel. First, dlCR2-pIX-dsRed-infected cells were stained for acetylated tubulin, a marker of microtubule stability (Westermann and Weber, 2003) (Figure 4a). Infected cells contained large amounts of acetylated tubulin organized in a ring, whereas acetylated microtubule fibers were dispersed in the cytoplasm in control cells. Second, immunoblots also demonstrated increased tubulin acetylation after adenovirus infection (Figure 4b and Supplementary Figure 2), but the addition of low-dose paclitaxel could not stabilize microtubules further. Finally, in a microtubule polymerization assay, the amount of polymerized tubulin increased from 16 to $34 \%$ following dl922-947 (multiplicity of infection (MOI) 10) infection. Low-dose paclitaxel alone increased polymerization $(30 \%)$ but, at MOI 10, there was no significant increase in the presence of both virus and drug (Figure 4c). Modulating acetylated tubulin levels by HDAC6 inhibition, 

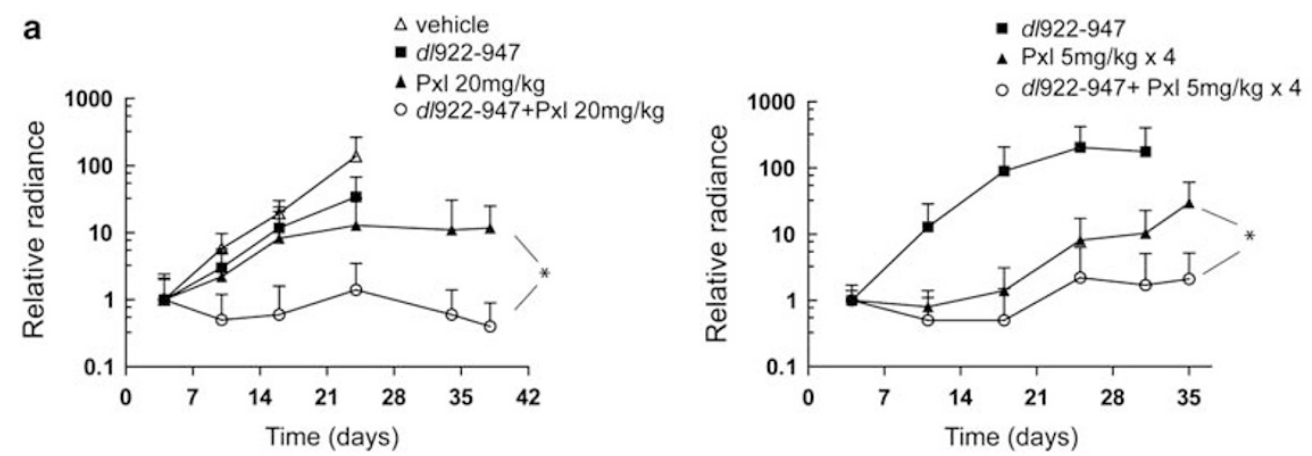

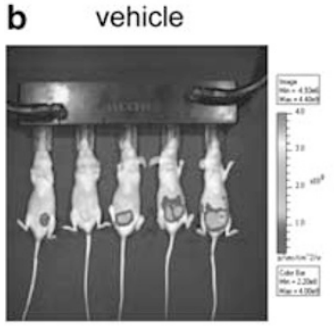

C
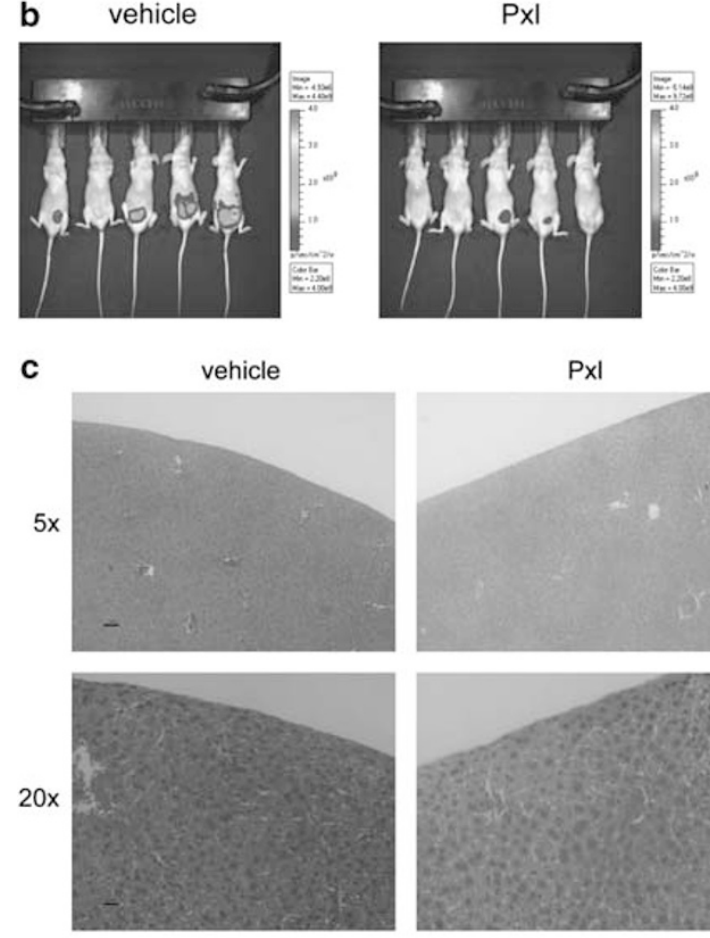

Pxl
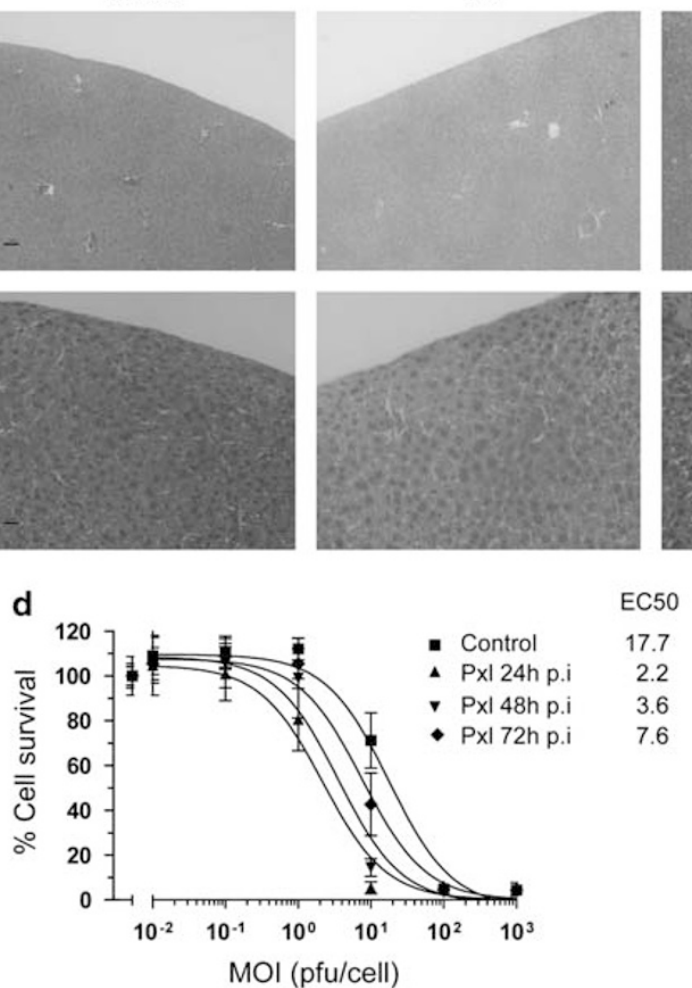

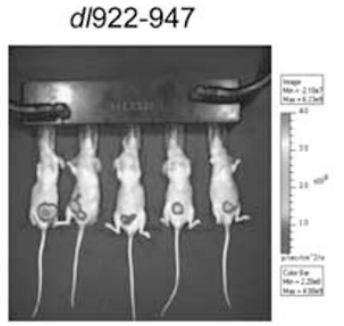

d1922-947
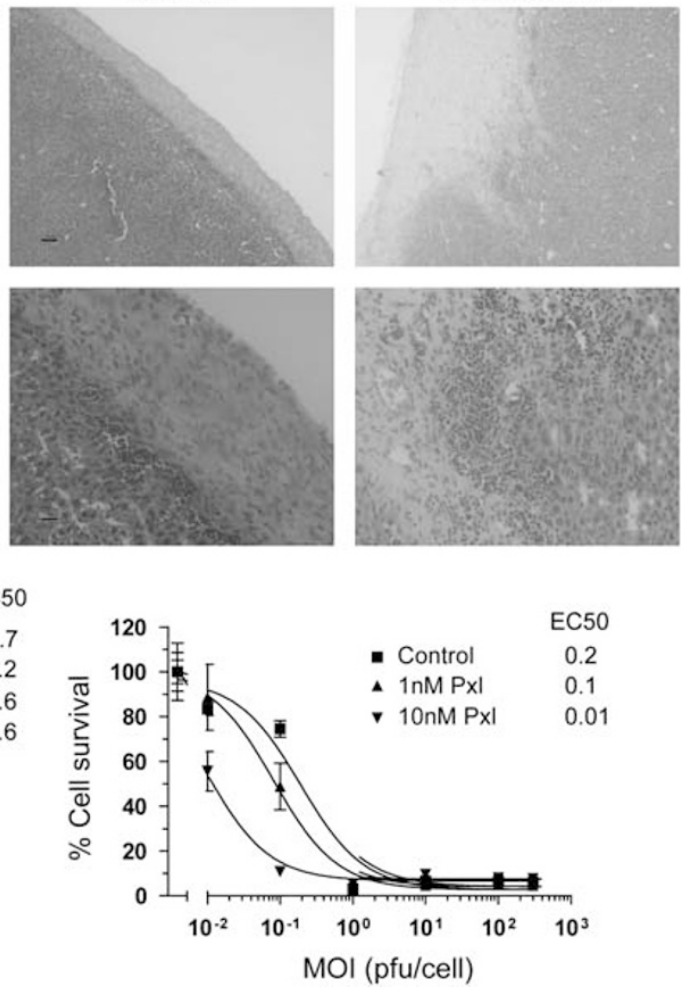

Figure 1 dl922-947 synergizes with paclitaxel in vitro and in vivo. (a) Female BALB C nude mice (5 mice/group) were injected i.p. with $3 \times 10^{6}$ A2780CP luciferase cells on day 1 followed by paclitaxel $(20 \mathrm{mg} / \mathrm{kg})$ or $d l 922-947\left(5 \times 10^{9}\right.$ particles $)$ treatment on day 5 . The combination group was treated with paclitaxel on day 6. Treatments were repeated weekly for 3 weeks (left). $d l 922-947$ was given weekly on days 4,11 and 18 . ${ }^{*} P=0.046$, one-tailed, unpaired Student's $t$-test. Low-dose paclitaxel (5 mg/kg) was administered i.p. daily for 4 days starting on days 5, 12 and 19 (right panel). $* P=0.044$ (one-tailed, unpaired Student's $t$-test). (b) Day 24 bioluminescence images from (a) (left). (c) Histopathology of livers from mice in (a). (Left) $4 \mu \mathrm{m}$ liver sections were stained with H\&E. (d) A2780CP cells were infected with $d l 922-947$ and treated with $3 \mathrm{~nm}$ paclitaxel up to $72 \mathrm{~h}$ post-infection (p.i.; left). Cell survival was analyzed by MTT assay. Calculated EC50 values are shown (p.f.u./cell). IGROV1 cells were infected as above and treated with 1 or 10 nm paclitaxel 24 hours p.i. (right).

however, did not affect viral efficacy (Supplementary Figure 3). Taken together, these data suggest that tubulin is stabilized at later time points after adenovirus infection but that low-dose paclitaxel does not synergize with $d / 922-947$ by augmenting this tubulin stabilization. 

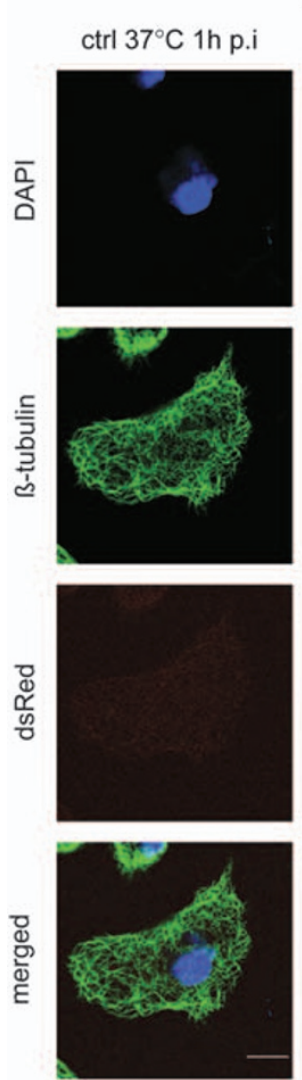

b

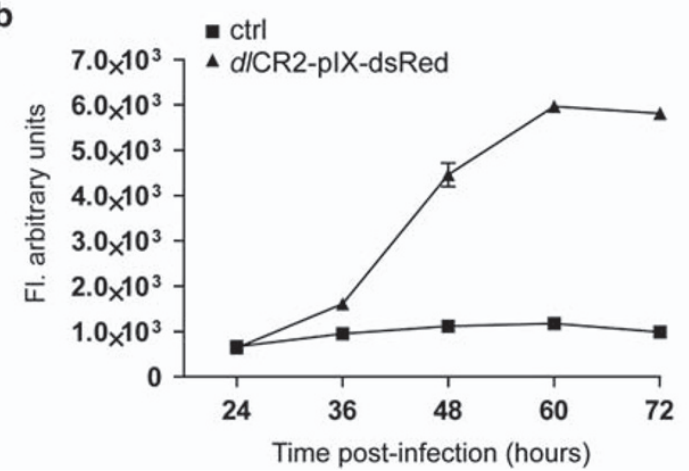

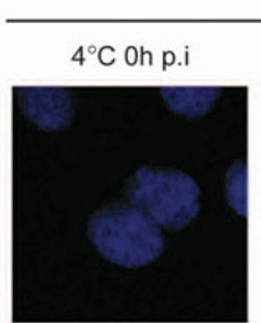
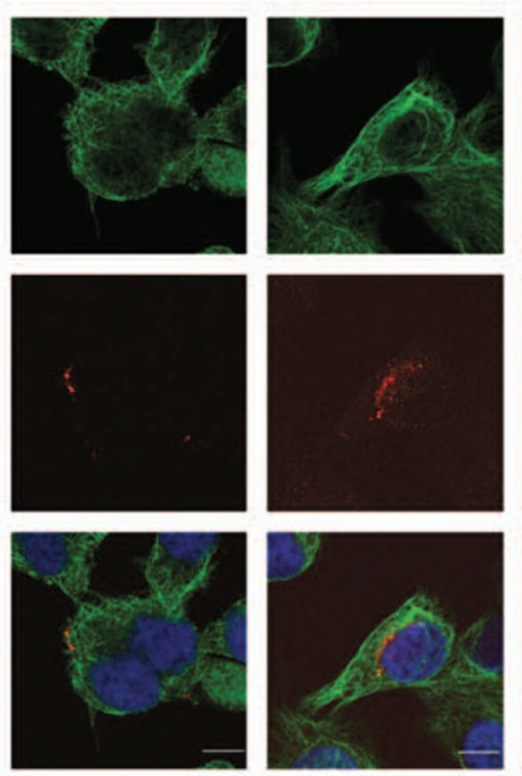

C
dICR2-plX-dsRed
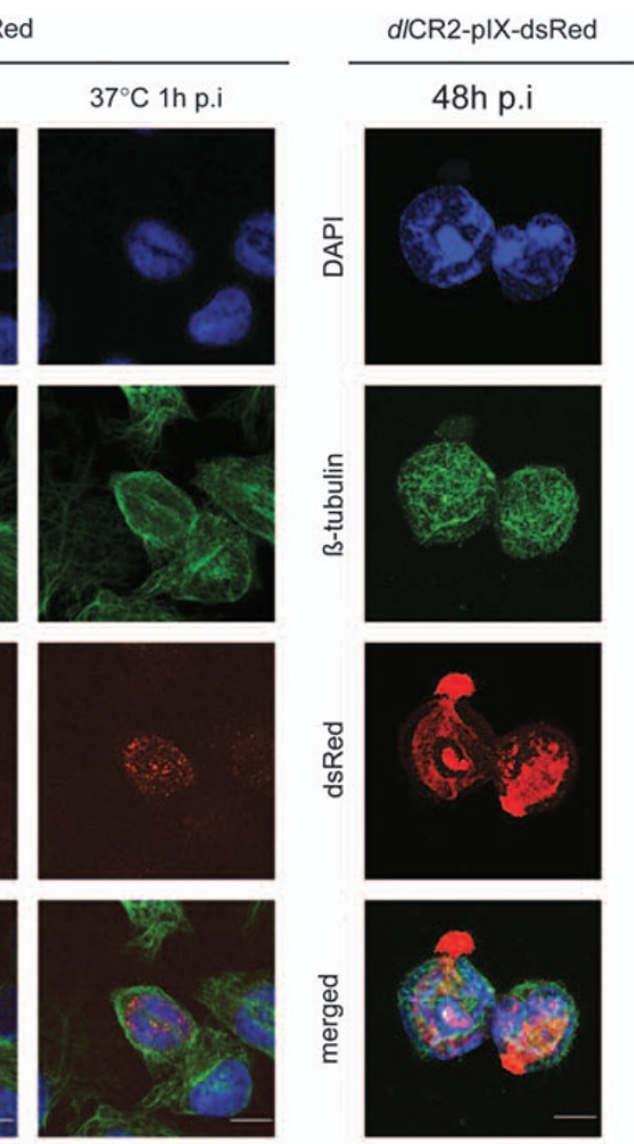

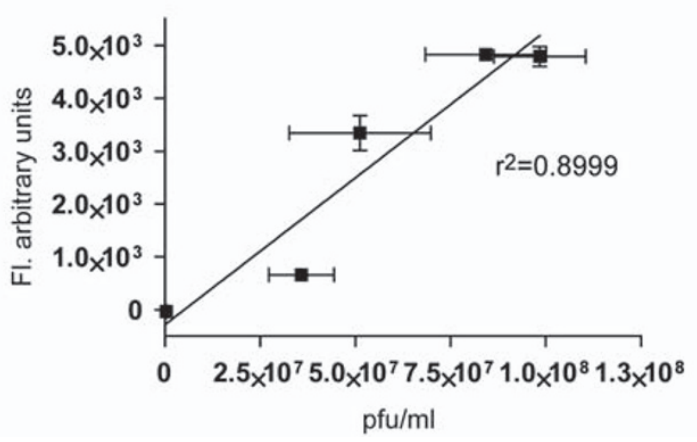

Figure 2 Use of $d l C R 2$-pIX-dsRed to monitor infection, virus replication and exit. (a) Visualization of viral entry and exit. IGROV1 cells were infected with $d l \mathrm{CR} 2$-pIX-dsRed on ice for $1 \mathrm{~h}\left(0 \mathrm{~h}\right.$ p.i. timepoint). Cells were warmed to $37^{\circ} \mathrm{C}$ for $1 \mathrm{~h}$, stained with $\beta$-tubulin, DAPI and subjected to confocal analysis (left). Scale bar $=10 \mu \mathrm{m}$. A2780CP cells were infected with dlCR2-pIX-dsRed (MOI 1) and analyzed as above $48 \mathrm{~h}$ p.i. (right). (b) A2780CP cells were infected with $d l \mathrm{CR} 2$-pIX-dsRed (MOI 1). The emitted fluorescence was measured with a plate reader in $12 \mathrm{~h}$ intervals up to $72 \mathrm{~h}$ p.i. (c) Scatter-plot analysis of data in B combined with intracellular viral replication as p.f.u./ml showing a correlation between fluorescence and intracellular viral replication $\left(r^{2}\right.$ value $\left.=0.8999\right)$.

Microtubules are important for adenovirus exit

We next determined whether paclitaxel and the microtubule network affected viral protein synthesis, replication and exit from cells. There were only minor changes in viral protein expression in the presence of three microtubule-targeting drugs, in particular no increase in E1A levels (Figure 5a). No change in intracellular viral replication in the presence of paclitaxel or nocodazole was seen (Figure 5b). However, there was a significant decrease in virus release with $300 \mathrm{~nm}$ nocodazole: $5.3 \times 10^{6}$ p.f.u. $/ \mathrm{ml}$ without nocodazole vs $2.1 \times 10^{5}$ p.f.u./ml with nocodazole, $P=0.005$. Paclitaxel, by contrast, had no effect on release (Figure $5 b$ ). Nocodazole (300 nM) induces a strong G2/M arrest in A2780CP cells (Supplementary Figure 4). To distinguish whether adenoviral release depends upon mitotic progression or functional microtubules, dl922-947-infected cells were treated with dimethylenastron, an inhibitor of the mitotic motor protein Eg5, which induces mitotic arrest without targeting the microtubule network (Gartner et al., 2005). As before, nocodazole significantly decreased the amount of virus released without altering 
a
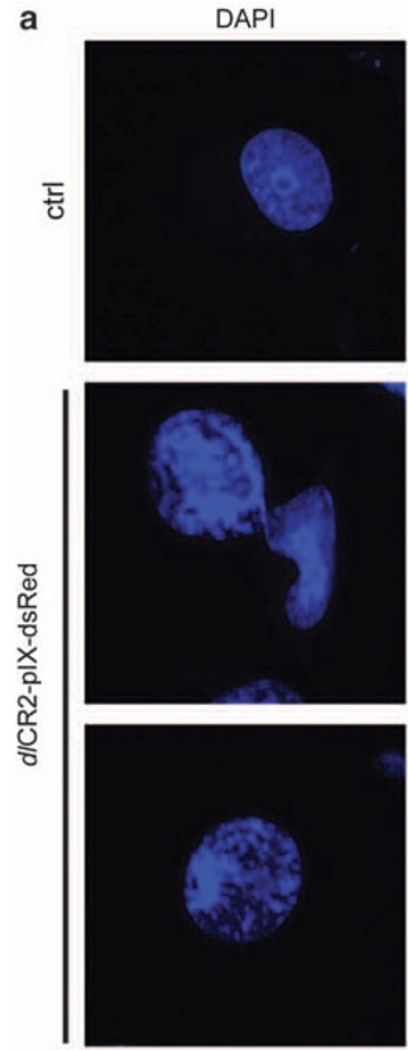

b

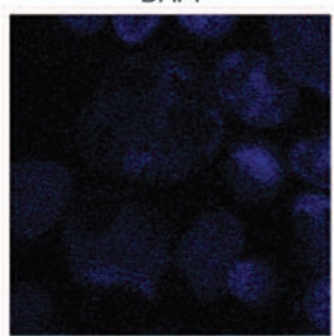

B-tubulin
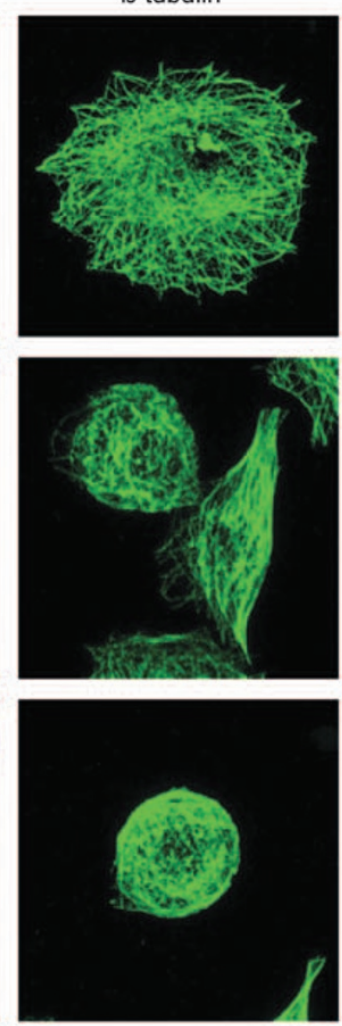

B-tubulin

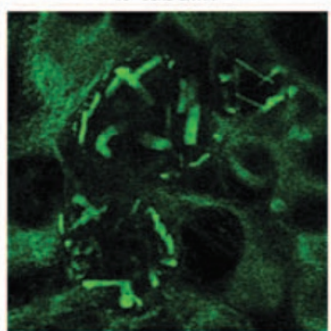

dsRed
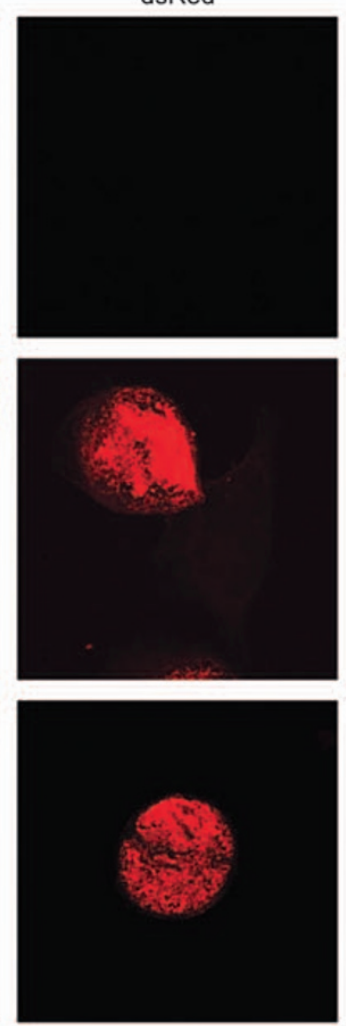

dsRed

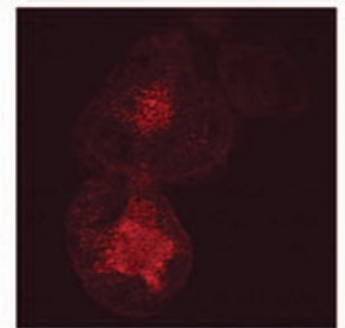

merged
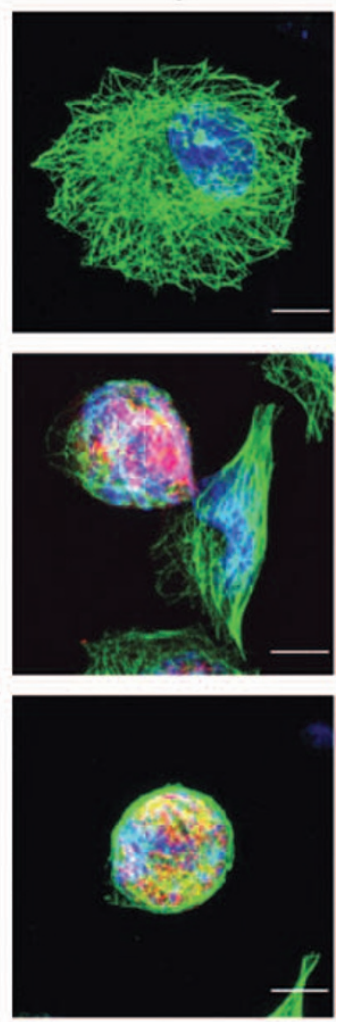

merged

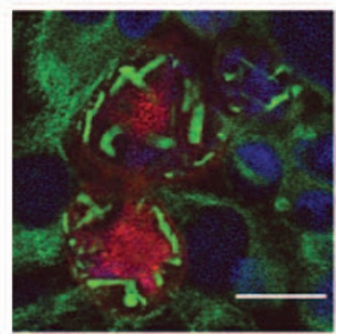

Figure 3 Adenovirus induces rearrangements of the microtubule network in ovarian cancer cells. (a) A2780CP cells were infected with dlCR2-pIX-dsRed (MOI 0.1), fixed in ice-cold methanol $48 \mathrm{~h}$ p.i., stained with antibodies against $\beta$-tubulin and counterstained with DAPI. Cells were analyzed by confocal microscopy. Scale bar $=10 \mu \mathrm{m}$. (b) IGROV1 cells were infected on ice for $1 \mathrm{~h}$. Unbound particles were washed off and the infection continued at $37^{\circ} \mathrm{C}$. Cells were fixed $72 \mathrm{~h}$ post-infection, stained and analyzed as in (a). Scale bar $=20 \mu \mathrm{m}$.

intracellular replication $(P \leqslant 0.01)$. By contrast, dimethylenastron, which induced a similar degree of cell cycle arrest as nocodazole (Supplementary Figure 4), had no effect upon virus release, despite a small but significant increase in intracellular $d l 922-947$ replication $\left(1.3 \times 10^{7}\right.$ vs $2.4 \times 10^{7}$ p.f.u. $/ \mathrm{ml}, P=0.016$; Figure $\left.5 \mathrm{c}\right)$. To ensure that the microtubule-targeting drugs were not altering virus release by affecting cell lysis, a lactate dehydrogenase release assay was performed. Lactate dehydrogenase release was low in dl922-947-infected cells, and the combination of virus and microtubuletargeting drugs did not increase cell lysis further (Supplementary Figure 5A). In addition, there was an inverse correlation between cell lysis and cell viability in both A2780CP and IGROV1 cells infected with either $d l 922-947$ or $d l 309$ (Supplementary Figure 5B). This indicated that virus is released from intact, viable cells through a microtubule-dependent pathway of non-lytic virus exit. However, paclitaxel does not utilize this pathway to synergize with adenovirus. This was reinforced by RNAi-mediated downregulation of CLASP proteins, which will reduce microtubule stability without causing depolymerization, and had minimal effects on virus release (Supplementary Figure 6).

\section{Low-dose paclitaxel deregulates mitotic progression,} associated with mitotic slippage, multinucleation and apoptosis

We then investigated cell cycle changes: we have previously shown that $d / 922-947$ can override multiple cell cycle checkpoints (Connell et al., 2008), whereas low-dose paclitaxel causes aberrant mitosis and mitotic slippage rather than $\mathrm{G} 2 / \mathrm{M}$ arrest (Chen and Horwitz, 

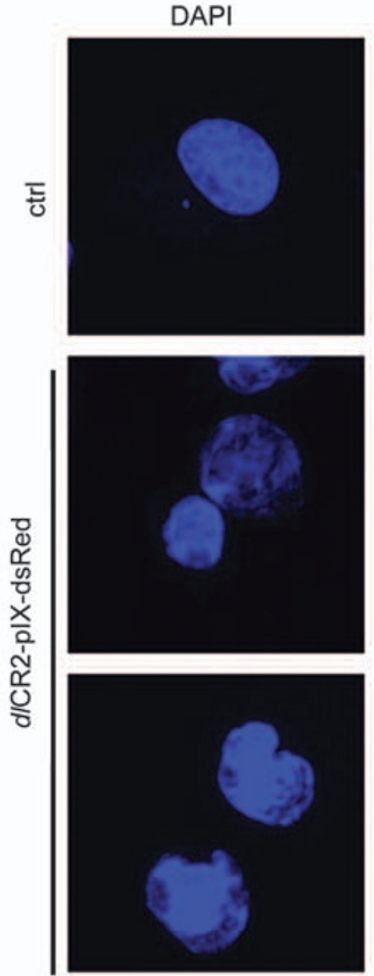

ac-tubulin
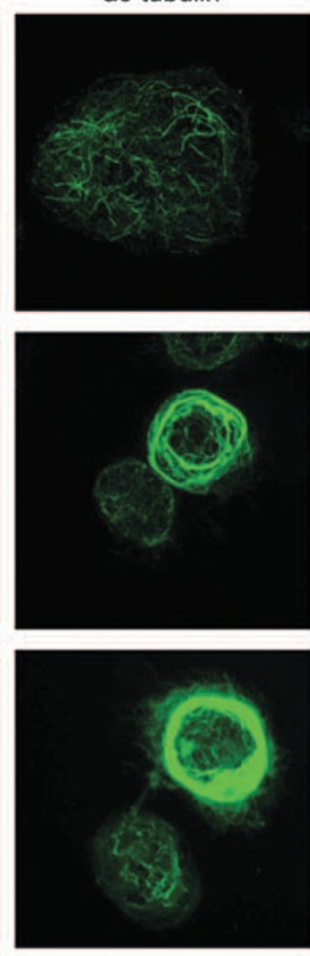

b

$$
\begin{array}{lllllllll}
- & - & - & - & 1 & 1 & 10 & 10 & d / 922-947(\mathrm{MOI}) \\
- & 1 & 10 & - & - & 1 & - & 1 & \operatorname{PxI}(\mathrm{nM}) \\
- & - & - & 200 & - & - & - & - & \operatorname{Noc}(\mathrm{nM})
\end{array}
$$
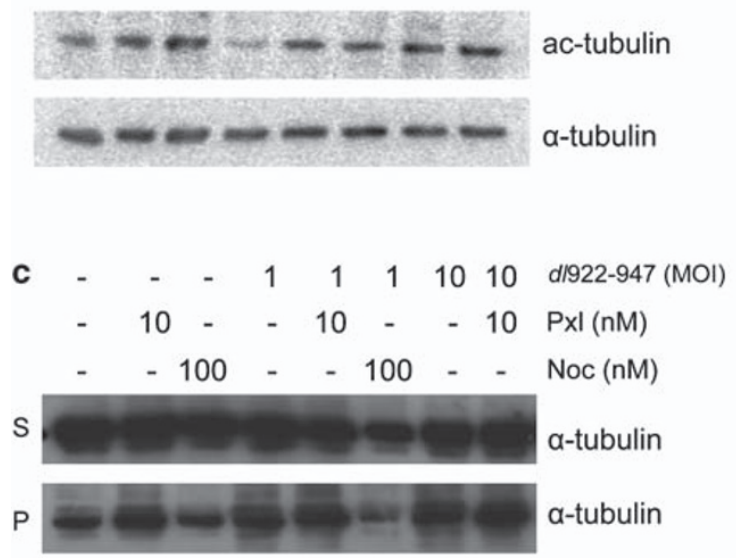
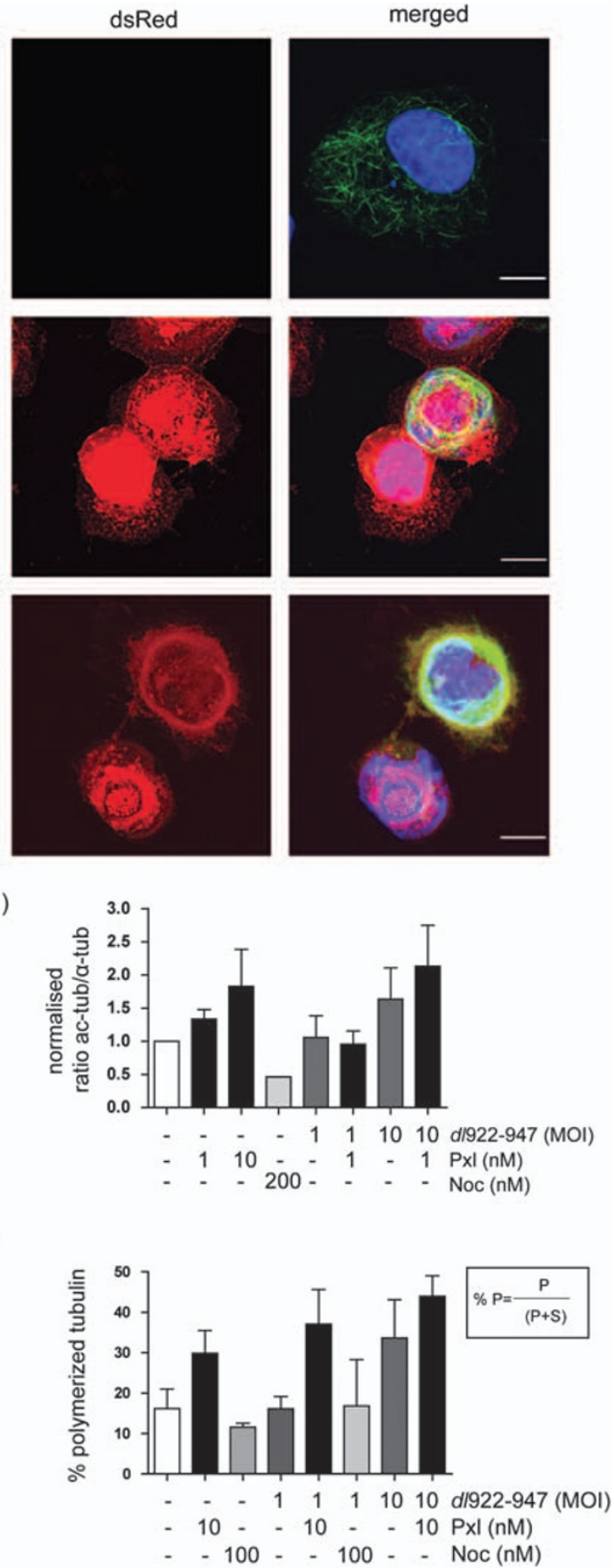

Figure 4 Microtubules are stable late after adenovirus infection. (a) A2780CP cell were infected with $d l$ CR2-pIX-dsRed (MOI 1). Cells were fixed in methanol and stained with antibodies against acetylated-tubulin. dlCR2-pIX-dsRed was detected in the dsRed channel. Scale bar $=10 \mu \mathrm{m}$. (b) IGROV1 cells were infected with dl922-947 (MOI 1 or 10) and treated with paclitaxel or nocodazole $24 \mathrm{~h}$ p.i. Protein bands on membranes were quantified on a phosphoimager (right). Ratios of acetylated tubulin/ $\alpha$-tubulin normalized to control cells are shown. Bars represent mean \pm s.e.m. (c) Microtubule polymerization assay. Soluble and insoluble microtubule fractions from dl922-947- and paclitaxel-treated cells were separated by centrifugation and analyzed by immunoblotting (left). Percentage polymerized tubulin was quantified according to the formula presented (right). Bars represent mean \pm s.e.m.

2002; Demidenko et al., 2008). Cells were first analyzed by immunofluorescence, revealing a population of multinucleated cells and cells with multipolar spindles following treatment with paclitaxel alone or in combination (Figure 6a). However, there was no significant change in the mitotic index after dl922-947 infection or combination treatment, indicating that cells do not accumulate in mitosis (Supplementary Figure 7).

By flow cytometry, $24 \mathrm{~h}$ of low-dose paclitaxel in A2780CP cells induced an increase in the sub-G1 
a
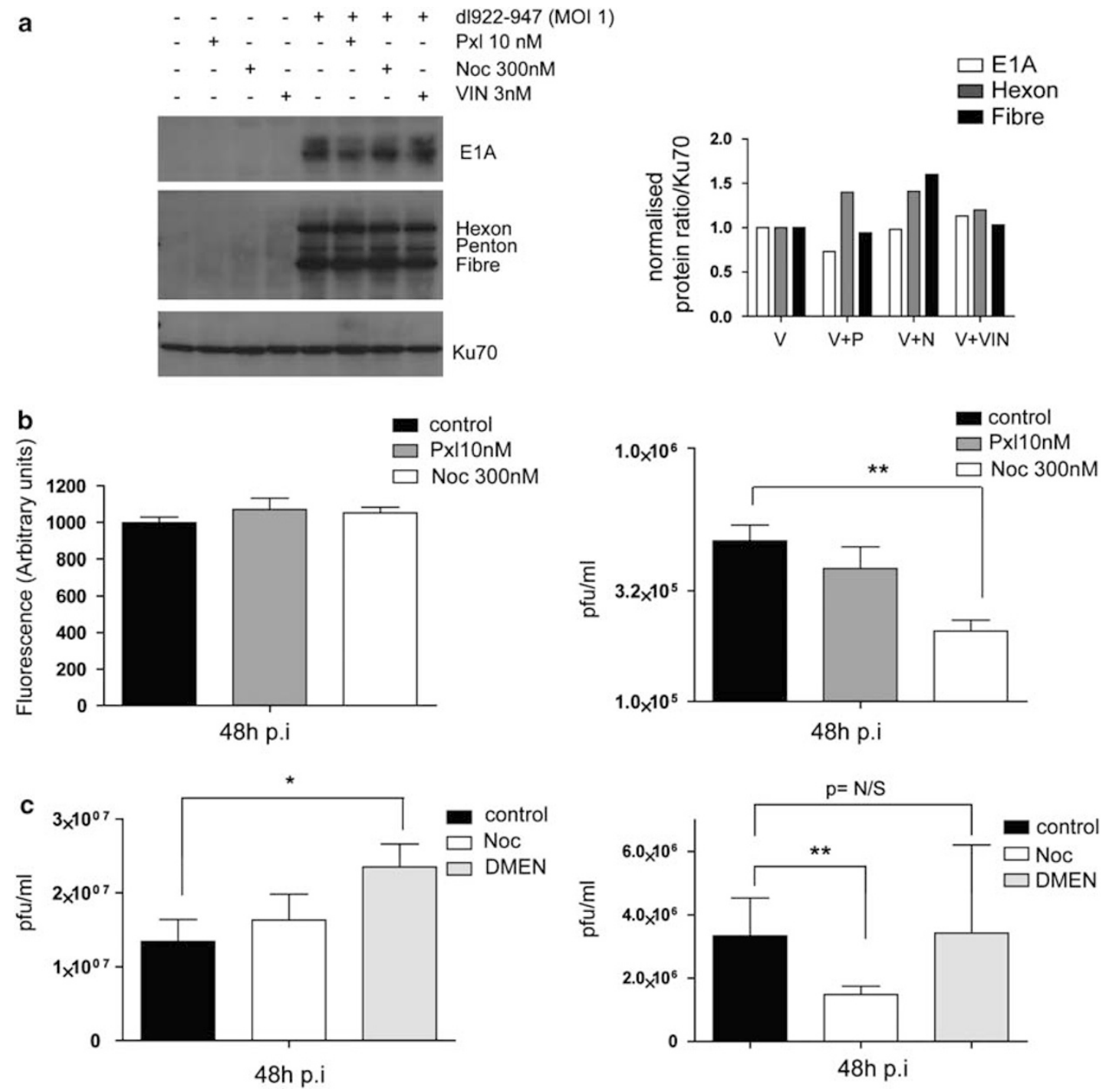

Figure 5 Microtubules are important for non-lytic adenoviral exit. (a) The effect of microtubule-targeting drugs on viral protein expression. Cells were infected with $d / 922-947$ (MOI 1) and treated with microtubule-targeting drugs $24 \mathrm{~h}$ p.i. Whole cell extracts were resolved on SDS-PAGE gels and immunoblotted with E1A and Ad5 antibodies $48 \mathrm{~h} \mathrm{p.i} \mathrm{(left).} \mathrm{Viral} \mathrm{protein} \mathrm{levels} \mathrm{were} \mathrm{quantified}$ on a phosphoimager. Ratios of E1A, hexon or penton to Ku70 normalized to dl922-947-infected cells (MOI 1) are shown (right). (b) A2780CP cells were infected with $d l \mathrm{CR} 2$-pIX-dsRed (MOI 1) and treated as in (a). Intracellular viral replication was assessed by fluorescence assay $48 \mathrm{~h}$ p.i. (left). Supernatants were collected and assayed for released infectious viral particles by TCID50 assay (right). (c) Intracellular viral replication and viral exit assays. A2780CP cells were infected with dl922-947 (MOI 10) and treated with nocodazole $(300 \mathrm{nM})$ or dimethylenastron $(1 \mu \mathrm{M}) 24 \mathrm{~h}$ p.i. Intracellular (left) and released (right) virus was titered on JH293 cells as in (b). ${ }^{*} P \leqslant 0.05 .{ }^{*} * P \leqslant 0.01$.

population only $(0.3 \%$ vs $10.4 \%)$ with no $\mathrm{G} 2 / \mathrm{M}$ arrest. d $1922-947$ alone produced a significant reduction in G1 (54.1\% vs $42.9 \%, P=0.008)$, with a small but significant increase in $>4 \mathrm{~N}$ population ( 2.5 vs $10.8 \%$ ). Combination treatment resulted in a profile with combined features: $9.8 \%$ sub-G1 and $13.3 \%>4 \mathrm{~N}$ (Figure $6 \mathrm{~b}$, upper panel), suggesting aberrant mitotic progression with apoptosis induction. Time-lapse microscopy of A2780CP-GFP-tubulin cells showed that paclitaxel, with or without $d l 922-947$, increased the percentage of cells dividing with multipolar spindles compared with dl922-947 or mock infection (Figure 6b, lower panel, Supplementary Figure 8). Thus, paclitaxel-treated cells and cells receiving combination treatment slip through mitosis in the presence of multipolar spindles to generate multiple and/or multinucleated daughter cells.

We next determined the expression and activity of the mitosis-promoting complex cyclin B1/cdk1 (Figure 6c, quantified in Supplementary Figure 9). There was an increase in cyclin B1 levels $48 \mathrm{~h}$ following dl922-947 infection. Surprisingly, cyclin B1 levels, the degradation of which is normally a prerequisite of mitotic exit (Pines, 2006), stayed high following paclitaxel treatment, suggesting either that cells can progress through mitosis in the presence of high levels of cyclin B1 or that degradation is slow or delayed. Levels of phosphohistone $\mathrm{H} 1$, a marker of cyclin $\mathrm{B} 1 / \mathrm{cdk} 1$ activity, rose after paclitaxel or dl922-947 alone, and increased further 
when the two were combined. Thus, both $d l 922-947$ and low-dose paclitaxel activate proteins involved in mitotic progression, confirming our previous finding that dl922-947 overrides multiple cell cycle checkpoints (Connell et al., 2008). This suggests again that paclitaxel/dl922-947 synergy results from mitotic slippage and multinucleation.

Aberrant mitosis can trigger an apoptotic response (Decordier et al., 2008). However, we have shown that oncolytic adenoviruses do not induce classical apoptosis
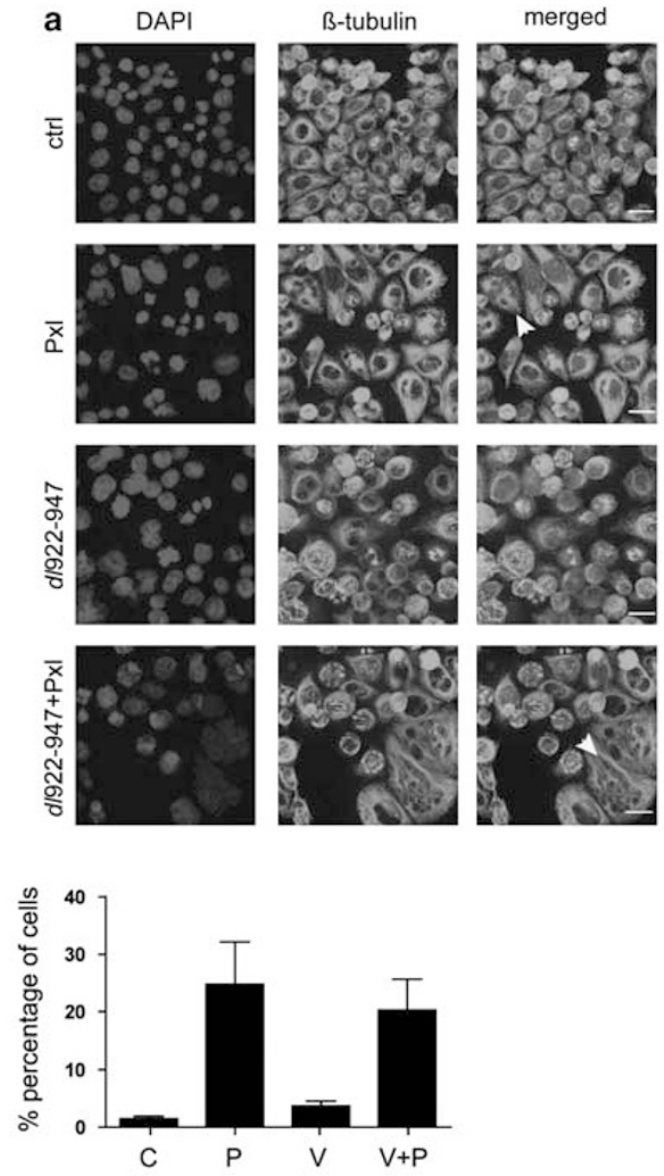

$\begin{array}{llllllllll}- & + & + & + & - & + & + & + & - & d / 922-947 \\ - & - & - & - & + & + & + & + & - & \mathrm{PxI} 10 \mathrm{nM}\end{array}$

C $24 \quad 48 \quad 72 \quad 24 \quad 48 \quad 4872 \quad \mathrm{~N}$ hours p.i

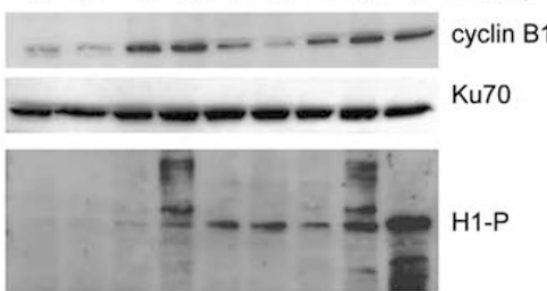

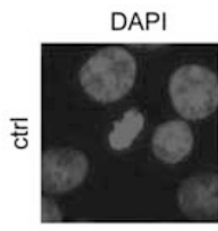
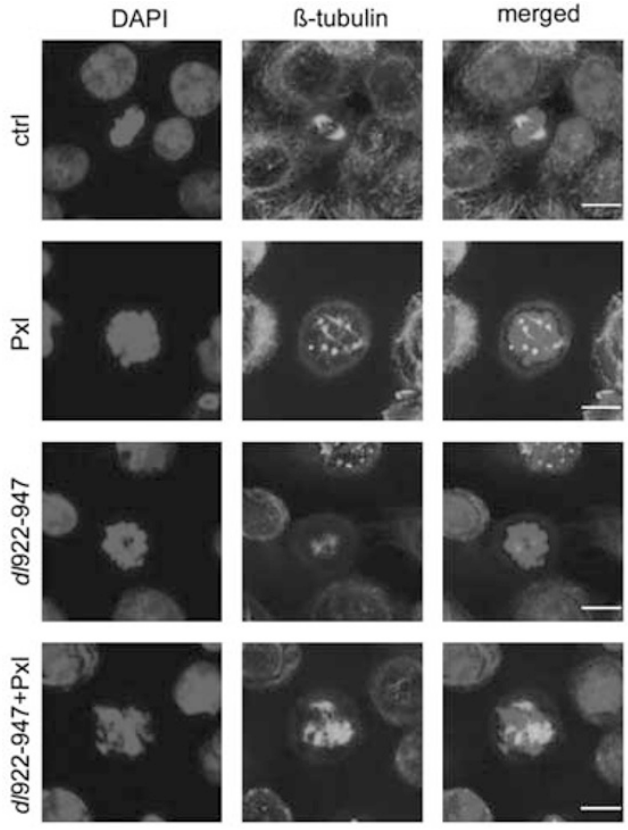

b
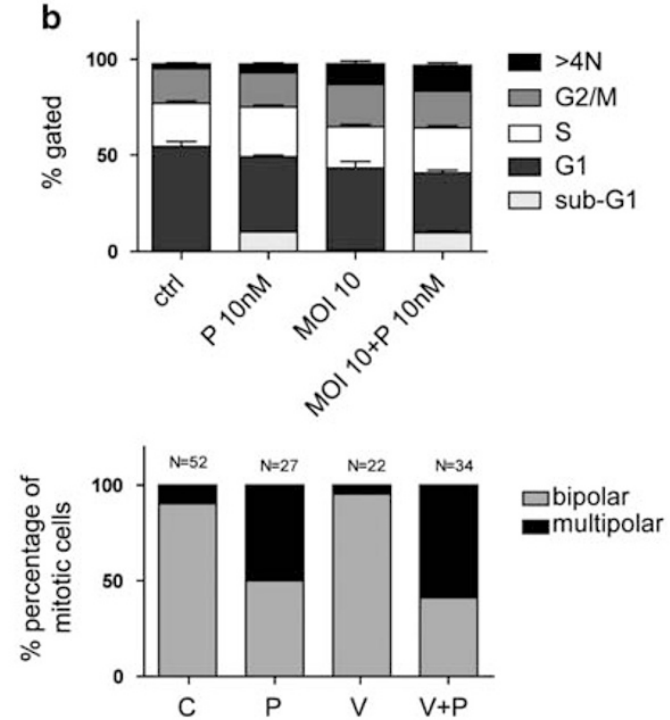
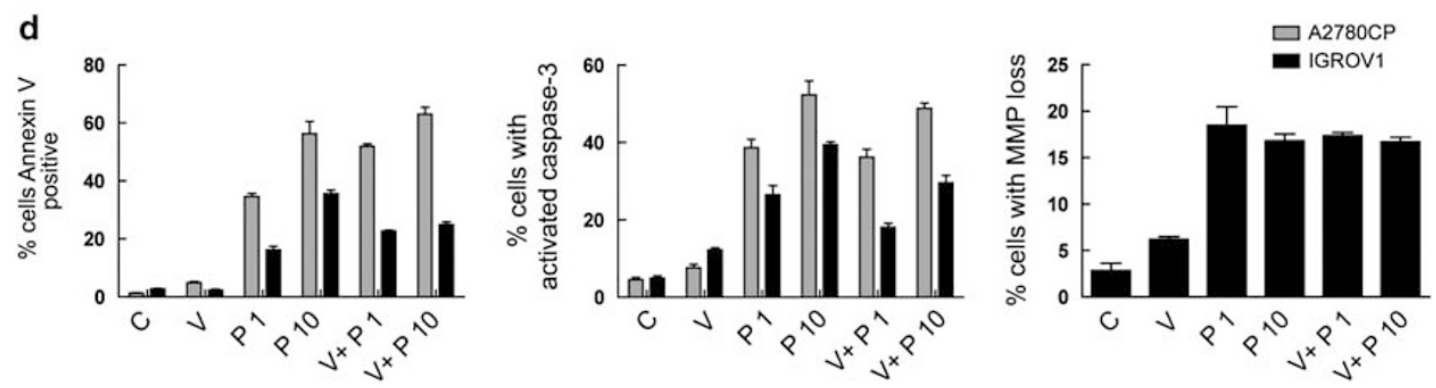
(Baird et al., 2008). To determine the effects of combination treatment, we analyzed cells for classical apoptosis markers (Figure 6d). As before, there was no increase in apoptosis in either A2780CP or IGROV1 following dl922-947 infection, whereas paclitaxel increased all markers in both cell lines. After combined treatment, high levels of activated caspase-3 and annexin- $\mathrm{V}$ positivity were seen again. Therefore, chemotherapy-induced apoptosis is dominant over the virusinduced death pathway when combining paclitaxel and dl922-947, although, interestingly, the presence of virus slightly reduced the effect when compared with paclitaxel alone.

\section{Discussion}

One strategy to increase oncolytic virus gene therapy efficacy in clinical trials is to combine it with chemotherapy. Here, we show that paclitaxel synergizes with the oncolytic adenovirus dl922-947 both in vitro and in vivo in the aggressive ovarian cancer xenograft model A2780CP by a mechanism of mitotic slippage leading to apoptosis.

We first studied host-cell microtubules because paclitaxel is a microtubule-stabilizing drug and adenoviruses require microtubules for nuclear transport. In agreement with others (Staufenbiel et al., 1986; Warren et al., 2006), we demonstrate that adenovirus induces wholesale microtubule rearrangements and that microtubules are stabilized. We also show, for the first time, that microtubules are important for viral exit independently of cell lysis. However, modulating the stability of microtubules either by inhibition of HDAC6 or by downregulating CLASP $1 / 2$ does not alter oncolytic efficacy and viral exit, respectively. Thus, microtubules are important for non-lytic adenoviral exit, but their stabilization is not fundamental to the viral lifecycle. Nocodazole at high concentration has been shown to induce actin stress fibre formation and cell contraction (Chang et al., 2008). Thus, the actin cytoskeleton may also have a role in non-lytic adenoviral exit. Further work is required to assess the contribution of the actin network in non-lytic adenoviral exit.

Microtubule stability and increased infectivity also could not explain the synergy between paclitaxel and dl922-947. At MOI 10, microtubules are already stable in infected cells and paclitaxel did not increase this further. At the nanomolar concentrations required for these studies, paclitaxel did not cause mitotic arrest but led to mitotic slippage, multipolar mitosis and multinucleation, resulting in apoptosis, in agreement with others (Paoletti et al., 1997; Chen and Horwitz, 2002; Demidenko et al., 2008). The apoptotic effect of paclitaxel was retained when combined with $d l 922-947$, although we have previously shown that ovarian cancer cells do not die through classical apoptosis on exposure to dl922-947 (Baird et al., 2008). This will have implications for combination clinical trials in recurrent cancers, where multiple apoptosis abnormalities have been described (Reed, 2006).

Similar to others (Murray et al., 1982; Cherubini et al., 2006), we have shown that adenoviruses can abrogate multiple cell cycle checkpoints (Connell et al., 2008). Some adenoviral proteins can affect mitotic progression and induce apoptosis. Adenoviral E4orf4 interacts with the protein phosphatase $2 \mathrm{~A}$, thereby inactivating the anaphase-promoting complex and inducing apoptosis (Shtrichman et al., 1999; Kornitzer et al., 2001). In addition, it was recently shown that E4orf4 induces cell death by mitotic catastrophe ( $\mathrm{Li}$ et al., 2009). Adenovirus E1A and infection with $d l 1520$ have both been shown to increase Mad2 protein levels (Hernando et al., 2004; Cherubini et al., 2006). E1A can also induce centrosome amplification (De Luca et al., 2003) and adenovirus death protein interacts with MAD2B (Ying and Wold, 2003). Thus, cell cycle abrogation and mitotic catastrophe may have important roles in adenoviral-induced cell death. Work exploring the importance of the $>4 \mathrm{~N}$ DNA population in adenovirus-infected cells is ongoing.

In our experiments, cyclin B1/cdk1 activity increased in a time-dependent manner in dl922-947-infected cells, indicating that cells are able to enter mitosis. The degradation of cyclin $\mathrm{B} 1$ is a prerequisite for mitotic exit and mitotic slippage (reviewed in Pines, 2006). Cyclin B1 levels were relatively low in paclitaxel-treated cells. At the same time, there was a small increase in the number of mitotic cells, suggesting that cells do enter mitosis and cyclin B1 is possibly degraded as the cells slip through. To our surprise, cyclin B1 levels were high in the infected cells in the presence of paclitaxel. This supports our

\footnotetext{
Figure 6 dl922-947 in combination with low-dose paclitaxel leads to mitotic defects, spindle checkpoint override and apoptosis in ovarian cancer cells. (a) A2780CP cells were infected with $d / 922-947$ (MOI 10) and treated with $10 \mathrm{~nm}$ paclitaxel $24 \mathrm{~h}$ later. Cells were fixed in methanol $48 \mathrm{~h}$ p.i. and stained for $\beta$-tubulin and DAPI. Scale bar $=20 \mu \mathrm{m}$. Arrows denote micronucleated cells (left). Mitotic cells were analyzed with a $63 \times$ objective and a zoom of 3 (right panel). Scale bar $=10 \mu \mathrm{m}$. The number of micronucleated cells was counted. Data represent mean \pm s.d. from triplicate slides. $>200$ cells were counted per slide (bottom left). (b) A2780CP cells were infected with $d l 922-947$ (MOI 10) and treated with paclitaxel $24 \mathrm{~h}$ p.i. Cells were fixed and stained with propidium iodide and analyzed by flow cytometry (top). A2780CP GFP-tubulin cells were grown on poly-D-lysine-coated coverslips and infected with $d 1922-947$ (MOI 10). Cells were treated with $10 \mathrm{~nm}$ paclitaxel 24 hours p.i. and analyzed by timelapse microscopy. Images were acquired every $30 \mathrm{~min}$ for $>20 \mathrm{~h}$. The number of mitotic cells dividing with either bipolar or multipolar spindles was quantified. $\mathrm{N}$ represents the number of mitotic cells counted for each condition (bottom). (c) Immunoblot analysis of mitosis-regulating proteins in A2780CP cells. Cells were infected and treated with paclitaxel as in a. Proteins were extracted up to $72 \mathrm{~h} \mathrm{p.i.} \mathrm{and} \mathrm{analyzed} \mathrm{for} \mathrm{expression} \mathrm{of} \mathrm{cyclin} \mathrm{B1}$ and phosphorylated histone H1. Nocodazole-treated cells $(\mathrm{N})(300 \mathrm{nM})$ were included as a positive control for cyclin B1/cdk1 activity. (d) Cells were infected with $d / 922-947(\mathrm{~V})$ followed by paclitaxel (P) treatment at 1 and $10 \mathrm{~nm} 24 \mathrm{~h}$ p.i. $48 \mathrm{~h}$ p.i., cells were analyzed for the apoptosis markers Annexin-V, activated caspase-3 and TMRE staining by FACS.
} 
previous findings that $d l 922-947$ can abrogate multiple cell cycle checkpoints (Connell et al., 2008). The degradation of cyclin B1 might be inhibited or delayed in these cells, possibly mediated by inhibition of the APC by E4orf4. Further work assessing cyclin B1 degradation in single cells after infection would answer this question.

In summary, we have shown that paclitaxel synergizes with oncolytic adenovirus through a mechanism of mitotic slippage leading to multinucleation and apoptosis. Despite its mode of action as a microtubulestabilizing drug, paclitaxel's effects on viruses occur independently of microtubule stabilization. Given the importance of aberrant mitosis to the biology of viruses, our results suggest that drugs that interfere with mitotic checkpoints, such as aurora kinase inhibitors, may also be able to augment the efficacy of adenoviruses and offer the possibilities of new clinical trials.

\section{Materials and methods}

Cell lines, viruses, chemicals and siRNA

A2780CP and IGROV1 cells were cultured in Dulbecco's modified Eagle's medium plus penicillin and streptomycin and $10 \%$ fetal calf serum (PAA Laboratories, Pasching, Austria). A2780CP-GFP tubulin single-cell clones were generated following transfection with pEGFP-Tub (Clontech Laboratories, Inc., Saint-Germain-en-Laye, France), G418 selection, cell sorting and growth in 96-well plates. dl922-947 is an Ad5 vector deleted in amino acids 122-129 of E1A-CR2 as well as E3B (Heise et al., 2000). $d l 309$ is the wild-type control of $d l 922-947$, with full-length E1A and the same E3B deletion. The chemicals used in this study were paclitaxel and vincristine (chemotherapy pharmacy, St Bartholomew's Hospital, London), Nocodazole (Sigma, Poole, UK), MG132 (z-Leu-Leu-Leu-al) (Sigma), dimethylenastron (ALX-270-438-M001, Alexis Biochemicals, Nottingham, UK) and tubacin (a gift from Dr S Schreiber). CLASP siRNA sequences were based on published sequences (Mimori-Kiyosue et al., 2005). CLASP1 siRNA: 5'-GCCATTATGCCAACTATCT-3', CLASP2 siRNA: $5^{\prime}$-GTTCAGAAAGCCCTTGATG- ${ }^{\prime}$. All oligos were purchased from Dharmacon. ON-TARGETplus Control Pool (D-001810-10-20, Dharmacon, Epsom, UK) was used as scrambled control. Cell survival was assessed by MTT assay as before (Lockley et al., 2006).

\section{Generation of $\mathrm{dlCR}$-pIX-dsRed}

To generate $d l$ CR2-pIX-dsRed, dsRed was fused to the minor capsid protein pIX separated by a FLAG epitope and recombined into the $d l \mathrm{CR} 2$ plasmid. To allow for recombination, left- and right-arm homology sequences were generated flanking the pIX sequence. The left-arm homology sequence encoding pIX was fused in frame with a FLAG epitope and monomeric dsRed into the pDsRed-Monomer-N1 plasmid (Clontech). To generate the left-arm homology sequence, cDNA encoding the $p I X$ gene between Ad5 nt 3609-4028 was amplified using wild-type Ad5 as template. Sense and antisense primers were flanked by AgeI enzyme restriction sequences. A FLAG epitope sequence was incorporated in the antisense primer. Sense: $5^{\prime}$-ACCGGTATACCTGTGTGG AAGCCTGGA- ${ }^{\prime}$. Underlined nucleotides denotes the $\mathrm{AgeI}$ site, and nucleotides in bold correspond to Ad5 nt 2824-2844. Anti-sense: $5^{\prime}$-ACCGGTGCGTACTTCTTCTTCTTGTAGT CAACCGCATTGGGAGGGGAGGAAGCCTTCA-3'. Underlined nucleotides represent $A g e \mathrm{I}$, and nucleotides in bold the FLAG epitope. Ad5 nt 4000-4028 are shown after the FLAG epitope sequence. The PCR product was subcloned into the pCRII-TOPOVector (Invitrogen, Paisley, UK). The pIX fragment was cloned into pDsRed-Monomer-N1 to generate the left-arm homology pIX-FLAG-dsRed cassette. A right-arm homology sequence starting immediately after the pIX stop codon (nt 4032) was generated using wild-type Ad5 as template with the following primers. Sense: 5'-AAGCTTAACATAAA TAAAAAACCAGACTCTGTTTGG. Underlined nucleotides represent HindIII site; nucleotides in bold Ad5 nt 4032-4061. Anti-sense: $\quad 5^{\prime}$-AAGCTTTGACCCAGACTACGCTGACG. Underlined nucleotides represent HindIII; nucleotides in italics Ad5 nt 5339-5320. The fragment was subcloned into pCRIITOPOVector, and cloned into the right arm of the shuttle plasmid pSuperShuttle. A full description of pSuperShuttle is found elsewhere (Oberg et al., in preparation). The left-arm homology pIX-FLAG-dsRed cassette was excised from pDsRed-Monomer-N1 as a KpnI/NotI fragment and ligated into the left-arm of pSuperShuttle. pSuperShuttle -pIXFLAG-dsRed was then linearized to generate a fragment of the left and right homology arms. This fragment was recombined with the $d l$ CR2 plasmid (Leyton et al., 2006) in BJ5193 Escherichia coli. Positive recombinants were amplified and the final product transfected into 293 cells for virion production. Viruses were purified on double $\mathrm{CsCl}$ gradients.

\section{Immunofluorescence}

Cells were grown on poly-L-lysine (Sigma) coated coverslips and fixed in $100 \%$ methanol for $5 \mathrm{~min}$ at $-20^{\circ} \mathrm{C}$ followed by four washes in phosphate-buffered saline (PBS). Cells were then blocked in $1.5 \%$ bovine serum albumin and PBS-Tween $(0.05 \%$ Tween-20 in PBS) for $30 \mathrm{~min}$ at room temperature. Cells were washed once in PBS followed by incubation with primary antibodies for $1 \mathrm{~h}$ at room temperature, washed four times in PBS-Tween and incubated with secondary antibodies for $1 \mathrm{~h}$ at room temperature. Coverslips were washed followed by staining with $4^{\prime}, 6$-diamidino-2-phenylindole (DAPI, Invitrogen) for $1 \mathrm{~min}$. Cells were washed twice in PBS and mounted onto glass slides.

\section{Western blotting}

Cells were lysed in $200 \mu$ lysis buffer $(150 \mathrm{~mm} \mathrm{NaCl}, 50 \mathrm{~mm}$ Tris Base, $0.05 \%$ SDS, $1 \%$ Triton X-100, with Complete Protease inhibitor cocktail tablets (Roche Diagnostics $\mathrm{GmbH}$ ), $\mathrm{pH} 8)$ followed by sonication on ice. Whole-cell lysate $(20-30 \mu \mathrm{g})$ was resolved on SDS-polyacrylamide gels, and transferred to nitrocellulose membranes by semi-dry transfer (BioRad, Hemel Hempstead, UK). Unless otherwise stated, membranes were blocked in $4 \%$ non-fat milk in PBS-Tween $(0.1 \%)$, followed by overnight incubation with primary antibodies. Proteins were detected by enhanced chemiluminescence (Amersham). Cyclin $\mathrm{B} 1$ was detected by blocking membranes in 3\% bovine serum albumin-PBS/Tween for $1 \mathrm{~h}$ at room temperature. CLASP proteins were resolved on $6 \%$ SDS-PAGE gels and transferred onto nitrocellulose membranes by wet transfer. Membranes were blocked in $2 \%$ bovine serum albumin and $0.05 \%$ PBSTween for $2 \mathrm{~h}$ at room temperature followed by incubation with CLASP antibodies overnight at room temperature.

\section{Histone purification}

Cells were resuspended in $0.5 \%$ Triton X-100/PBS supplemented with protease and phosphatase inhibitors (Complete Protease inhibitor cocktail tablets and PhosSTOP Phosphatase Inhibitor Cocktail Tablets (Roche Diagnostics GmbH)) followed by incubation on ice for $10 \mathrm{~min}$. Cells were centrifuged at 2000 r.p.m., for $10 \mathrm{~min}$ at $4{ }^{\circ} \mathrm{C}$. Pellets were 
resuspended in 0.5 volume $0.5 \%$ Triton X-100/PBS and centrifuged as above. The remaining pellet was resuspended in $0.1 \mathrm{~N} \mathrm{HCl}$ and histones extracted overnight at $4{ }^{\circ} \mathrm{C}$. Samples were centrifuged and supernatant collected. In all, $20 \mu \mathrm{g}$ of extracted histones was analyzed on SDS-PAGE gel.

\section{Antibodies}

The following antibodies were used for immunoblots: CLASP1 (\#2292) and CLASP2 (\#2358) antibodies were a kind gift from Dr N. Galjart, (Akhmanova et al., 2001; Mimori-Kiyosue et al., 2005). Anti- $\alpha$-tubulin (Abcam, Cambridge, UK), anti-acetylatedtubulin (Sigma), anti-Adenovirus-2/5 E1A (Santa Cruz, Heidelberg, Germany), anti-Adenovirus5 (Abcam), anti-Ku70 (Santa Cruz), anti-cyclin B1 (BD Pharmingen, Oxford, UK), anti-Mad2L1 (Abcam), anti-phospho-histone H1, (Abcam). Primary antibodies for immunofluorescence were anti- $\beta$-tubulin (Sigma) and anti-acetylated-tubulin (Sigma).

\section{Tubulin polymerization assay}

Tubulin polymerization assays were based on those previously described (Giannakakou et al., 1998). Floating cells were collected by centrifugation and all cells were then lysed in $200 \mu \mathrm{l}$ hypotonic buffer $\left(37^{\circ} \mathrm{C}\right.$ in the dark). The buffer was complemented with Complete Protease inhibitor tablets (Roche, Welwyn Garden City, UK). Lysate was centrifuged (14000 r.p.m., room temperature $10 \mathrm{~min}$ ) and the supernatant (soluble fraction, S) removed. The insoluble fraction $(\mathrm{P})$ was resuspended in $200 \mu$ l hypotonic buffer. Both samples were incubated on ice, sonicated and mixed with $200 \mu 12 \times$ SDS loading buffer. $20 \mu \mathrm{l}$ was separated on SDS-PAGE gels.

Intracellular viral replication assay using dlCR2-pIX-dsRed These experiments used phenol red medium. $3 \times 10^{5}$ cells were seeded overnight in six-well plates, then washed in serum-free, phenol red-free medium. Cells were infected with dlCR2-pIXdsRed (MOI 1 p.f.u./cell) in $500 \mu 1$ serum-free medium without phenol red for $3 \mathrm{~h}$ and refed with phenol red-free medium $+2 \%$ fetal calf serum. The fluorescence was measured for $1 \mathrm{~s}$ using a Victor $^{3}$ TM1420 multilabel counter (Perkin Elmer, Buckinghamshire, UK) with 544/15 nm excitation and $620 / 8 \mathrm{~nm}$ emission filters. Fluorescent averages were calculated and values for untreated cells subtracted from those of infected cells to reveal the net mean fluorescence. After each scan, cells were scraped in medium and centrifuged (5 min, 1500 r.p.m.), washed in $0.1 \mathrm{~m}$ Tris, $\mathrm{pH} 8$, and re-pelleted. Cells were resuspended in $0.1 \mathrm{M}$ Tris $\mathrm{pH} 8$ followed by three rounds of freeze thawing (liquid $\mathrm{N}_{2} / 37^{\circ} \mathrm{C}$ ). Virus was titered on $\mathrm{JH} 293$ cells. For viral exit assays, medium was collected from virusinfected cells and centrifuged for $5 \mathrm{~min}$ at 4000 r.p.m. The supernatant was titered.

\section{Flow cytometry}

Cells were fixed in ice-cold $70 \%$ ethanol and fixed for $>30 \mathrm{~min}$ at $4{ }^{\circ} \mathrm{C}$ followed by centrifugation at 1500 r.p.m. for $5 \mathrm{~min}$. Pellets were washed in PBS, resuspended in $50 \mu 1$ of $100 \mu \mathrm{g} / \mathrm{ml}$ of Ribonuclease A, (R-4642) (Sigma) in PBS and incubated at $37^{\circ} \mathrm{C}$ for $15 \mathrm{~min}$. Cells were then stained with propidium iodide (Invitrogen, Molecular Probes, Paisley, UK) to a final concentration of $50 \mu \mathrm{g} / \mathrm{ml}$ and analyzed by flow cytometry (BD FACS Calibur, Becton Dickinson, Oxford, UK).

\section{Microscopy and live-cell imaging}

Hematoxylin and eosin slides were analyzed with an Axiophot microscope (Zeiss, Jena, Germany) coupled to a Nikon Digital Camera, DXM1200. Images were acquired with $\times 5$ or $\times 20$
Plan-Neofluar objectives (Zeiss). Confocal analysis was performed with an inverted Zeiss LSM 510 META laserscanning microscope with a Plan-Apochromat $\times 63 / 1.4$ oil objective. DAPI was detected with a 405-nm laser, Alexa Fluor 488 with a 488-nm laser and dsRed with a 543-nm laser. Images were acquired in the $x, y, z$ direction, with a line average of 4 except for Figure $1 \mathrm{~b}$ and Supplementary Figure 1, where images were acquired in the $x, y$ direction with a line average of 8 . Z-sections were acquired at optimum interval levels with sections of $0.36-0.43 \mu \mathrm{m}$. Microscope settings were kept the same for all images in each experiment. Maximal intensity Z-projections were assembled with the LSM5 Image browser software.

A2780CP GFP-tubulin cells were grown on poly-D-lysinecoated glass bottom culture dishes (MatTek Corporation, Ashland, MA, USA). The medium was changed to Leibovitz's L-15 medium without phenol red (21083, GIBCO, Invitrogen) before imaging. Images were acquired in a closed system at $37^{\circ} \mathrm{C}$ with a motorized, epi-fluorescence, inverted Zeiss Axiovert $200 \mathrm{M}$ microscope coupled to a Hamamatsu Orca 12 bit, $1280 \times 1280$ pixel CCD camera. To detect GFP-tubulin, images were acquired every $30 \mathrm{~min}$ over $24 \mathrm{~h}$ with an LD-Aplan $\times 20$ objective (Zeiss), exposure time of $1.5 \mathrm{~s}$ and gain of 100. Autoexposure was performed for every third image throughout. Films were assembled with the Simple PCI software (Digital Pixel) and processed in ImageJ.

\section{In vivo experiments}

Experiments were carried out under suitable UK Home Office personal and project license authority, using 6-8-week-old female $\mathrm{BALB} / \mathrm{c} n u / n u$ mice (Harlan, Huntington, UK). In experiment $1,3 \times 10^{6}$ A2780CP-luciferase cells were injected i.p. on day 1 . Mice received three weekly doses of $d l 922-947$ $\left(5 \times 10^{9}\right.$ particles $)$ and $/$ or paclitaxel $(20 \mathrm{mg} / \mathrm{kg})$ starting at day 5. Combination treatments were separated by $24 \mathrm{~h}$, with virus injected first. In experiment 2, paclitaxel was fractionated into four daily doses of $5 \mathrm{mg} / \mathrm{kg}$ on days $5-8$ commencing $24 \mathrm{~h}$ after dl922-947. All mice were assessed daily for weight, general health and accumulation of ascites and were killed according to UK Home Office guidelines. At post-mortem, livers were harvested, fixed in $10 \%$ formaldehyde $(\mathrm{w} / \mathrm{v})$ and $4 \mu \mathrm{m}$ sections stained with hematoxylin and eosin.

Mice were anesthetized ( $2 \%$ isofluorane by inhalation) and injected i.p. with $125 \mathrm{mg} / \mathrm{kg}$ D-luciferin (Calliper Life Sciences, Runcorn, UK). Five minutes later, although still under anesthetic, they were placed in a light-tight chamber on a warmed stage $\left(37^{\circ} \mathrm{C}\right)$ and light emission from a defined region of interest on a ventral surface was imaged on a Xenogen IVIS 100 Imaging System (Alameda, CA, USA). Data were analyzed using Living Image software (also Xenogen) and are presented as mean radiance (photons $/ \mathrm{s} / \mathrm{cm}^{2} / \mathrm{sr}$ ).

\section{Apoptosis assays}

Cells were incubated with $40 \mathrm{~nm}$ tetramethylrhodamine ethyl ester perchlorate (Invitrogen) for $10 \mathrm{~min}$, washed in PBS and resuspended with Annexin V-Alexa 647 conjugate $(2.5 \mu \mathrm{g} / \mathrm{ml})$ for $15 \mathrm{~min}$. DAPI $(1 \mu \mathrm{g} / \mathrm{ml})$ was then added. For caspase activation analysis, cells were incubated for $60 \mathrm{~min}$ with $10 \mu \mathrm{M}$ PhiPhiLux- $\mathrm{G}_{1} \mathrm{D}_{2}$ substrate (OncoImmunin Inc, Gaithersburg, MD, USA) before DAPI addition, then analyzed on a FACS LSRII (Becton Dickinson) and the data processed using FlowJo software (Tree Star, Ashland, OR, USA).

\section{Cell lysis assay}

Lactate dehydrogenase activity in the medium was measured with the Cytotoxicity Detection Kit (lactate dehydrogenase) 
(Roche Applied Science). The absorbance values were read at 490 and $630 \mathrm{~nm}$ with a Victor ${ }^{3}$ TM 1420 multilabel counter (Perkin Elmer). The net absorbance was calculated by subtracting the average reference $630 \mathrm{~nm}$ values from the average $490 \mathrm{~nm}$ readings.

\section{Statistics}

All statistical analyses were generated with GraphPad Prism 5.00 (San Diego, CA, USA). All statistical analyses are unpaired, two-tailed, Student's $t$-test unless otherwise stated.

\section{References}

AbouEl Hassan MA, Braam SR, Kruyt FA. (2006). Paclitaxel and vincristine potentiate adenoviral oncolysis that is associated with cell cycle and apoptosis modulation, whereas they differentially affect the viral life cycle in non-small-cell lung cancer cells. Cancer Gene Ther 13: 1105-1114.

Akhmanova A, Hoogenraad CC, Drabek K, Stepanova T, Dortland B, Verkerk T et al. (2001). Clasps are CLIP-115 and -170 associating proteins involved in the regional regulation of microtubule dynamics in motile fibroblasts. Cell 104: 923-935.

Baird SK, Aerts JL, Eddaoudi A, Lockley M, Lemoine NR, McNeish IA. (2008). Oncolytic adenoviral mutants induce a novel mode of programmed cell death in ovarian cancer. Oncogene 27: 3081-3090.

Belin MT, Boulanger P. (1987). Processing of vimentin occurs during the early stages of adenovirus infection. J Virol 61: 2559-2566.

Chang YC, Nalbant P, Birkenfeld J, Chang ZF, Bokoch GM. (2008). GEF-H1 couples nocodazole-induced microtubule disassembly to cell contractility via RhoA. Mol Biol Cell 19: 2147-2153.

Chen JG, Horwitz SB. (2002). Differential mitotic responses to microtubule-stabilizing and-destabilizing drugs. Cancer Res 62: $1935-1938$.

Cheong SC, Wang Y, Meng JH, Hill R, Sweeney K, Kirn D et al. (2008). E1A-expressing adenoviral E3B mutants act synergistically with chemotherapeutics in immunocompetent tumor models. Cancer Gene Ther 15: 40-50.

Cherubini G, Petouchoff T, Grossi M, Piersanti S, Cundari E, Saggio I. (2006). E1B55K-deleted adenovirus (ONYX-015) overrides G1/S and $\mathrm{G} 2 / \mathrm{M}$ checkpoints and causes mitotic catastrophe and endoreduplication in p53-proficient normal cells. Cell Cycle 5: $2244-2252$.

Connell CM, Wheatley SP, McNeish IA. (2008). Nuclear survivin abrogates multiple cell cycle checkpoints and enhances viral oncolysis. Cancer Res 68: 7923-7931.

De Luca A, Mangiacasale R, Severino A, Malquori L, Baldi A, Palena A et al. (2003). E1A deregulates the centrosome 5cycle in a Ran GTPase-dependent manner. Cancer Res 63: 1430-1437.

Decordier I, Cundari E, Kirsch-Volders M. (2008). Survival of aneuploid, micronucleated and/or polyploid cells: crosstalk between ploidy control and apoptosis. Mutat Res 651: 30-39.

Demidenko ZN, Kalurupalle S, Hanko C, Lim CU, Broude E, Blagosklonny MV. (2008). Mechanism of G1-like arrest by low concentrations of paclitaxel: next cell cycle p53-dependent arrest with sub G1 DNA content mediated by prolonged mitosis. Oncogene 27: 4402-4410.

Felsani A, Mileo AM, Paggi MG. (2006). Retinoblastoma family proteins as key targets of the small DNA virus oncoproteins. Oncogene 25: 5277-5285.

Flak MB, Connell CM, Chelala C, Archibald K, Salako MA, Pirlo KJ et al. (2010). p21 Promotes oncolytic adenoviral activity in ovarian cancer and is a potential biomarker. Mol Cancer 9: 175.

Gartner M, Sunder-Plassmann N, Seiler J, Utz M, Vernos I, Surrey T et al. (2005). Development and biological evaluation of potent and specific inhibitors of mitotic Kinesin Eg5. Chembiochem 6: 1173-1177.

\section{Conflict of interest}

The authors declare no conflict of interest.

\section{Acknowledgements}

We thank Dr Stuart Schreiber (Broad Institute, Harvard University) and the Initiative for Chemical Genetics, National Cancer Institute, USA, for providing tubacin. We also thank Dr Niels Galjart for CLASP antibodies.
Giannakakou P, Villalba L, Li H, Poruchynsky M, Fojo T. (1998). Combinations of paclitaxel and vinblastine and their effects on tubulin polymerization and cellular cytotoxicity: characterization of a synergistic schedule. Int $J$ Cancer 75: 57-63.

Hecht JR, Bedford R, Abbruzzese JL, Lahoti S, Reid TR, Soetikno RM et al. (2003). A phase I/II trial of intratumoral endoscopic ultrasound injection of ONYX-015 with intravenous gemcitabine in unresectable pancreatic carcinoma. Clin Cancer Res 9: 555-561.

Heise C, Hermiston T, Johnson L, Brooks G, Sampson-Johannes A, Williams A et al. (2000). An adenovirus E1A mutant that demonstrates potent and selective systemic anti-tumoral efficacy. Nat Med 6: 1134-1139.

Hernando E, Nahle Z, Juan G, Diaz-Rodriguez E, Alaminos M, Hemann $\mathrm{M}$ et al. (2004). Rb inactivation promotes genomic instability by uncoupling cell cycle progression from mitotic control. Nature 430: 797-802.

Jordan MA, Toso RJ, Thrower D, Wilson L. (1993). Mechanism of mitotic block and inhibition of cell proliferation by taxol at low concentrations. Proc Natl Acad Sci USA 90: 9552-9556.

Katsumata N, Yasuda M, Takahashi F, Isonishi S, Jobo T, Aoki D et al. (2009). Dose-dense paclitaxel once a week in combination with carboplatin every 3 weeks for advanced ovarian cancer: a phase 3 , open-label, randomised controlled trial. Lancet 374: 1331-1338.

Kornitzer D, Sharf R, Kleinberger T. (2001). Adenovirus E4orf4 protein induces PP2A-dependent growth arrest in Saccharomyces cerevisiae and interacts with the anaphase-promoting complex cyclosome. J Cell Biol 154: 331-344.

Le LP, Everts M, Dmitriev IP, Davydova JG, Yamamoto M, Curiel DT. (2004). Fluorescently labeled adenovirus with pIX-EGFP for vector detection. Mol Imaging 3: 105-116.

Le T, Hopkins L, Baines KA, Rambout L, Al Hayki M, Kee Fung MF. (2006). Prospective evaluations of continuous weekly paclitaxel regimen in recurrent platinum-resistant epithelial ovarian cancer. Gynecol Oncol 102: 49-53.

Leopold PL, Crystal RG. (2007). Intracellular trafficking of adenovirus: many means to many ends. Adv Drug Deliv Rev 59: 810-821.

Leyton J, Lockley M, Aerts JL, Baird SK, Aboagye EO, Lemoine NR et al. (2006). Quantifying the activity of adenoviral E1A CR2 deletion mutants using renilla luciferase bioluminescence and 3'-deoxy-3'-[18F]fluorothymidine positron emission tomography imaging. Cancer Res 66: 9178-9185.

Li S, Szymborski A, Miron MJ, Marcellus R, Binda O, Lavoie JN et al. (2009). The adenovirus E4orf4 protein induces growth arrest and mitotic catastrophe in H1299 human lung carcinoma cells. Oncogene 28: 390-400.

Lockley M, Fernandez M, Wang Y, Li NF, Conroy S, Lemoine N et al. (2006). Activity of the adenoviral E1A deletion mutant d1922947 in ovarian cancer: comparison with E1A wild-type viruses, bioluminescence monitoring, and intraperitoneal delivery in icodextrin. Cancer Res 66: 989-998.

Markman M, Hall J, Spitz D, Weiner S, Carson L, Van Le L et al. (2002). Phase II trial of weekly single-agent paclitaxel in platinum/ paclitaxel-refractory ovarian cancer. J Clin Oncol 20: 2365-2369. 
McGuire WP, Hoskins WJ, Brady MF, Kucera PR, Partridge EE, Look KY et al. (1996). Cyclophosphamide and cisplatin compared with paclitaxel and cisplatin in patients with stage III and stage IV ovarian cancer. $N$ Engl J Med 334: 1-6.

Meulenbroek RA, Sargent KL, Lunde J, Jasmin BJ, Parks RJ. (2004). Use of adenovirus protein IX (pIX) to display large polypeptides on the virion-generation of fluorescent virus through the incorporation of pIX-GFP. Mol Ther 9: 617-624.

Mimori-Kiyosue Y, Grigoriev I, Lansbergen G, Sasaki H, Matsui C, Severin F et al. (2005). CLASP1 and CLASP2 bind to EB1 and regulate microtubule plus-end dynamics at the cell cortex. $J$ Cell Biol 168: 141-153.

Murray JD, Bellett AJ, Braithwaite A, Waldron LK, Taylor IW. (1982). Altered cell cycle progression and aberrant mitosis in adenovirus-infected rodent cells. J Cell Physiol 111: 89-96.

Paoletti A, Giocanti N, Favaudon V, Bornens M. (1997). Pulse treatment of interphasic $\mathrm{HeLa}$ cells with nanomolar doses of docetaxel affects centrosome organization and leads to catastrophic exit of mitosis. J Cell Sci 110(Part 19): 2403-2415.

Pines J. (2006). Mitosis: a matter of getting rid of the right protein at the right time. Trends Cell Biol 16: 55-63.

Reed JC. (2006). Drug insight: cancer therapy strategies based on restoration of endogenous cell death mechanisms. Nat Clin Pract Oncol 3: 388-398.

Seidman MA, Hogan SM, Wendland RL, Worgall S, Crystal RG, Leopold PL. (2001). Variation in adenovirus receptor expression and adenovirus vector-mediated transgene expression at defined stages of the cell cycle. Mol Ther 4: 13-21.

Sherr CJ, McCormick F. (2002). The RB and p53 pathways in cancer. Cancer Cell 2: 103-112.

Shtrichman R, Sharf R, Barr H, Dobner T, Kleinberger T. (1999). Induction of apoptosis by adenovirus E4orf4 protein is specific to transformed cells and requires an interaction with protein phosphatase 2A. Proc Natl Acad Sci USA 96: 10080-10085.

Staufenbiel M, Epple P, Deppert W. (1986). Progressive reorganization of the host cell cytoskeleton during adenovirus infection. $J$ Virol $\mathbf{6 0}$ : 1186-1191.

Tollefson AE, Scaria A, Hermiston TW, Ryerse JS, Wold LJ, Wold WS. (1996). The adenovirus death protein (E3-11.6K) is required at very late stages of infection for efficient cell lysis and release of adenovirus from infected cells. J Virol 70: 2296-2306.

Warren JC, Rutkowski A, Cassimeris L. (2006). Infection with replication-deficient adenovirus induces changes in the dynamic instability of host cell microtubules. Mol Biol Cell 17: 3557-3568.

Westermann S, Weber K. (2003). Post-translational modifications regulate microtubule function. Nat Rev Mol Cell Biol 4: 938-947.

White E, Cipriani R. (1989). Specific disruption of intermediate filaments and the nuclear lamina by the $19-\mathrm{kDa}$ product of the adenovirus E1B oncogene. Proc Natl Acad Sci USA 86: 9886-9890.

Ying B, Wold WS. (2003). Adenovirus ADP protein (E3-11.6K), which is required for efficient cell lysis and virus release, interacts with human MAD2B. Virology 313: 224-234.

Supplementary Information accompanies the paper on the Oncogene website (http://www.nature.com/onc) 